\title{
ANÁLISES SOBRE MUDANÇAS NOS HÁBITOS ALIMENTARES DE CRIANÇAS MORADORAS DO ASSENTAMENTO PAQUEQUER, NOVA OLINDA DO NORTE- AM.
}

\section{Analysis about changes in the food habits of children living in Paquequer Settlement, Nova Olinda do Norte - AM.}

\begin{abstract}
Ingrid Silva de Freitas Graduanda em Geografia Bacharelado na Universidade Federal do Amazonas - UFAM. Pesquisadora do Núcleo de Estudos e Pesquisas das Cidades da Amazônia - NEPECAB. Bolsista de PIBIC- CNPQ. ingrid is@hotmail.com

José Aldemir de Oliveira Professor Titular de Geografia da Universidade Federal do Amazonas, pesquisador do CNPq e professor nos Programas de Pós-Graduação Sociedade e Cultura e Geografia da UFAM.

jaldemir@pq.cnpq.br

Cinthya Martins Jardim Doutoranda em Sociedade e Cultura da Amazônia. Mestre em Sociedade e Cultura da Amazônia. Bolsista da Fundação de Amparo à Pesquisa do Estado do Amazonas (FAPEAM). Pesquisadora do Núcleo de Estudos e Pesquisas das Cidades da Amazônia- NEPECAB. cinthyajardim@hotmail.com
\end{abstract}

RESUMO: As informações apresentadas neste artigo resultam do trabalho de iniciação científica no PIB-H/0083/2015-CNPq, realizados no Projeto de Assentamento Paquequer, município de Nova Olinda do Norte - Amazonas, no ano de 2015. O assentamento pesquisado configura um modelo de assentamento tradicional, localizado em ecossistema amazônico de terra firme distante $13 \mathrm{~km}$ da sede do município. Participaram da pesquisa, crianças moradoras do assentamento, matriculadas no Ensino Fundamental II da Escola Municipal Paquequer. O objetivo da pesquisa buscou analisar como se apresentava o consumo alimentar do universo pesquisado, tanto em sua moradia quanto no ambiente escolar, verificando se nesses locais poderiam ser identificadas mudanças nos hábitos alimentares regionais. Os dados obtidos no resultado final da pesquisa confirmaram que, nos últimos anos, o consumo de alimentos ultraprocessados como refrigerantes, biscoitos recheados e embutidos é amplamente realizado pelos entrevistados dentro do assentamento, em detrimento do consumo reduzido de frutas, peixes e alimentos tradicionalmente regionais, demonstrando que cada vez mais os padrões alimentares urbanos estão sendo vivenciados no modo de vida rural.

Palavras-Chave: Assentamentos Rurais, Hábitos alimentares, Segurança alimentar.

ABSTRACT: The information presented in this article results from the work of scientific initiation PIBIC$\mathrm{H} / 0083 / 2015-\mathrm{CNPQ}$, carried out in the settlement project Paquequer, municipal of Nova Olinda do Norte-Am, in the year 2015. The traditional settlement located in Amazonian ecosystem of dry, land distant $13 \mathrm{~km}$ from the seat of the municipality. Participants of the survey were children living in the settlement enrolled in elementary education II of the Municipal Paquequer School. The research sought 
ANÁLISES SOBRE MUDANÇAS NOS HÁBITOS ALIMENTARES DE CRIANÇAS MORADORAS DO ASSENTAMENTO PAQUEQUER, NOVA OLINDA DO NORTE- AM.

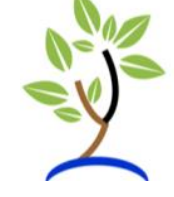

to analyze how the food consumption of the food universe studied was presented, both in their homes and in the school environment, verifying if they could identify changes in the regional food habits. The data obtained in the research results confirm that, in recent years, the consumption of ultraprocessed products such as soft drinks, biscuits and sausages is widely performed by the respondents within the establishment, to the detriment of the reduced consumption of fruit, fish and traditionally regional foods, demonstrating that each time More urban eating patterns are being experienced in the rural way of life

Key-Words: Rural settlements; Alimentary habits; Food security.

\section{INTRODUÇÃO}

Este artigo apresenta resultados obtidos em pesquisa acadêmica de iniciação científica do PIBIC realizada em 2015, junto ao curso de Bacharelado em Geografia pela Universidade Federal do Amazonas - UFAM. A pesquisa inicial teve como título: Abordagens sobre os hábitos alimentares no cotidiano de crianças em idade escolar, moradoras de assentamentos rurais, tendo sido realizada, como estudo comparativo, em dois assentamentos amazônicos: $\mathrm{Na}$ área de várzea, no município de Manacapuru- Amazonas e área de terra firme, no município de Nova Olinda do Norte - Amazonas.

O recorte realizado no referido trabalho de pesquisa, apresenta neste artigo somente as informações coletadas junto às crianças matriculadas na Escola Municipal Paquequer, localizada no Projeto de Assentamento Paquequer, pertencente ao município de Nova Olinda do Norte - Amazonas. O objetivo da pesquisa buscou analisar como se apresentava o consumo alimentar desses alunos em sua moradia e no ambiente escolar, verificando se nesses locais poderiam ser identificadas mudanças nos hábitos alimentares regionais.

O Projeto de Assentamento Paquequer pertence ao município de Nova Olinda do Norte - Amazonas. Esse município está localizado à margem direita do rio Madeira, a $126 \mathrm{~km}$ de Manaus em linha reta e a $132 \mathrm{~km}$, via fluvial. Segundo os dados oficiais do Instituto Brasileiro de Geografia e Estatítica (IBGE), o município possui uma área de $5.586 .253 \mathrm{~km}^{2}$, apresentando as seguintes coordenadas geográficas: $3^{\circ} 45^{\prime} 23^{\prime \prime}$ de latitude sul e $59^{\circ} 3^{\prime 2} 23^{\prime \prime}$ de longitude oeste, tendo como limites: a leste, o município de 
ANÁLISES SOBRE MUDANÇAS NOS HÁBITOS ALIMENTARES DE CRIANÇAS MORADORAS DO ASSENTAMENTO PAQUEQUER, NOVA OLINDA DO NORTE- AM.

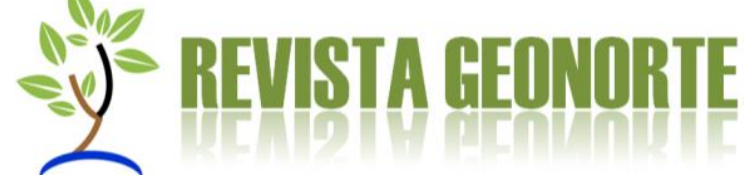

Maués; ao sul e oeste, o município de Borba; ao norte, o município de Autazes e a sudeste, o município de Itacoatiara. O Censo de 2010 informa que o município possui um total de 30.696 habitantes, com 17.070 residindo na zona rural e 13.626, na zona urbana.

O Projeto de Assentamento Paquequer, figura 1, foi criado através da Portaria do INCRA SR (15) n 112 de 27.11.98 publicado no Diário Oficial da União no 233 de 04.12.98. O assentamento possui uma área total de 5.354,4117 ha (Cinco mil, trezentos e cinquenta e quatro hectares, quarenta e um ares e dezessete centiares), localizado à margem esquerda da Estrada Vicinal de N.O.N-Curupira (AM 254), Km 15, Gleba de Abacaxis.

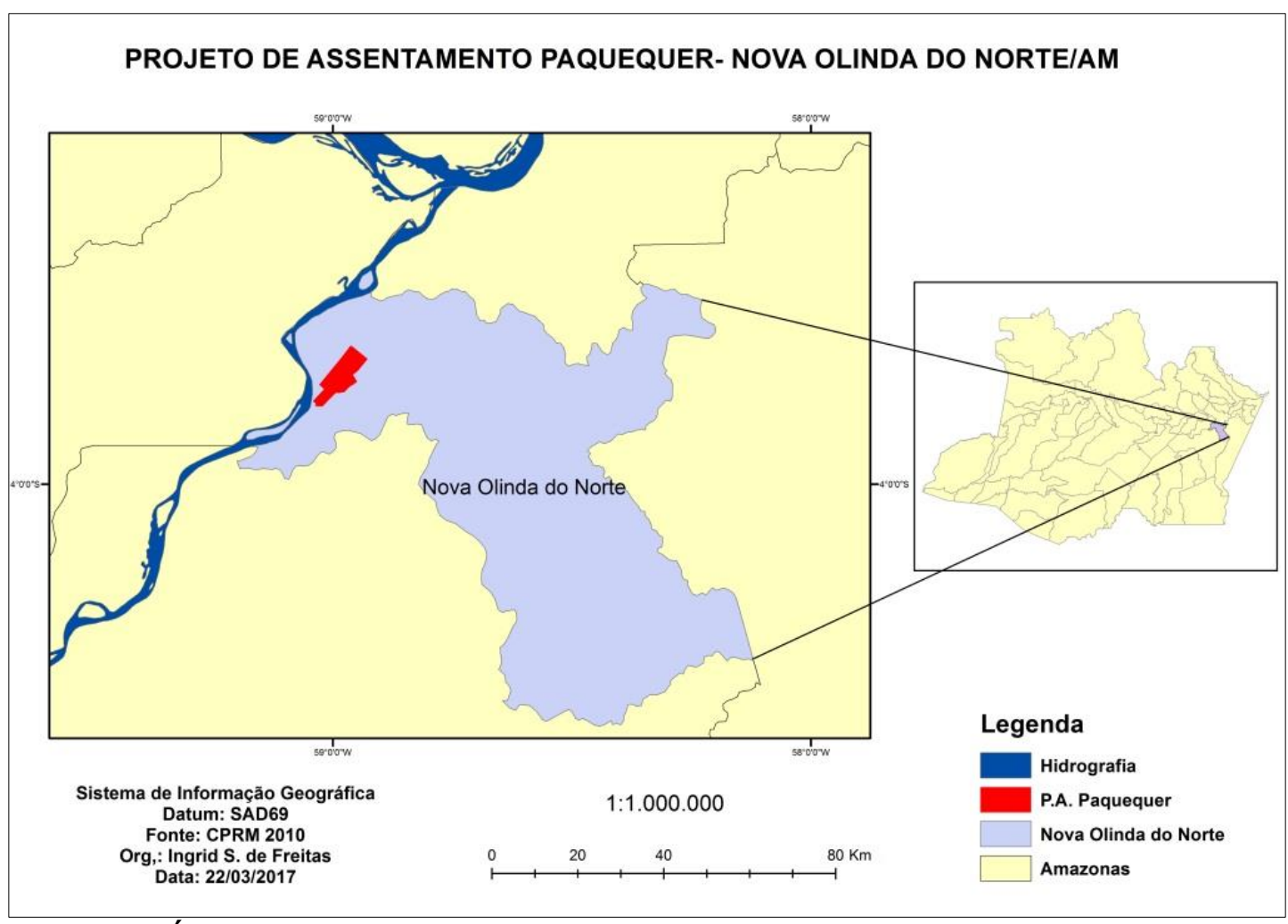

Figura 1- Área do Projeto de Assentamento Paquequer- Nova Olinda do Norte.

(Organização: Ingrid S. de Freitas. Data: 22/03/2017). 
ANÁLISES SOBRE MUDANÇAS NOS HÁBITOS ALIMENTARES DE CRIANÇAS MORADORAS DO ASSENTAMENTO PAQUEQUER, NOVA OLINDA DO NORTE- AM.

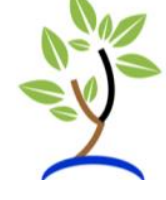

O assentamento foi fundado oficialmente em 05 de janeiro de 1999, tendo sido arrecadado através da Portaria INCRA/Distrito Federal - DF/№ 269, de30/11/1984 e matriculado em nome da União, sob o № 1.888, livro 2-2, folha 88/89, no Cartório de Registro de Nova Olinda do Norte. A partir de sua fundação, foi prevista a criação de 374 unidades agrícolas familiares, cabendo a cada uma delas, aproximadamente 14,316 hectares. Participaram da pesquisa, os filhos dos primeiros assentados que residem na área da Vicinal Paquequer (Lote1a176), a primeira área de lotes a ser ocupada dentro do assentamento, que se encontra grifada na planta abaixo.

As crianças que participaram da pesquisa eram matriculadas no Ensino Fundamental II da Escola Municipal Paquequer, localizada dentro do Projeto de Assentamento Paquequer. A pesquisa se justificou pela necessidade de avaliar como os hábitos alimentares de crianças moradoras de assentamentos rurais amazônicos de áreas de terra firme estão se modificando, uma vez que os participantes apresentaram novos padrões alimentares baseados no intenso consumo de alimentos industrializados, produtos enlatados, embutidos e frangos congelados. Este novo comportamento alimentar coloca em risco a saúde de populações que residem em zonas rurais do Amazonas, provocando um processo gradativo de desorganização sociocultural em toda Amazônia.

A globalização permitiu a divulgação das propagandas de bens alimentícios industrializados e instantâneos, estimulando os consumidores em todo planeta a incorporar novos padrões alimentares, utilizando amplamente alimentos congelados que vendem a ideia de praticidade em seu preparo associada à potencialização de seu sabor, tornando a sociedade contemporânea extremamente dependente das indústrias alimentícias que realizam uma feroz concorrência para conquistar o paladar do público alvo, investindo em cores e sabores quimicamente transformados (Moss, 2015). 
ANÁLISES SOBRE MUDANÇAS NOS HÁBITOS ALIMENTARES DE CRIANÇAS MORADORAS DO ASSENTAMENTO PAQUEQUER, NOVA OLINDA DO NORTE- AM.

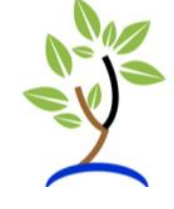

\section{MATERIAIS E MÉTODOS}

O trabalho de pesquisa foi fundamentado nos estudos multidisciplinares que são desenvolvidos pelo Núcleo de Estudos e Pesquisas das Cidades na Amazônia Brasileira (NEPECAB), especificamente pelo Projeto "Cidades Amazônicas: dinâmicas espaciais, rede urbana local e regional" (PRONEX/FAPEAM/CNPq). Também é importante ressaltar que pesquisas sobre mudanças nos hábitos alimentares amazônicos já foram realizadas em outras regiões brasileiras com o Projeto "Mapeamento isotópico da dieta no Brasil - dos núcleos mais isolados aos grandes centros urbanos" (Processo no 2011/50345-9, FAPESP). No Amazonas, especificamente na região do Rio Solimões, pesquisas foram desenvolvidas pelo Projeto: "Do peixe com farinha à macarronada com frango: uma análise das transformações da rede urbana no Médio e Alto Solimões pela perspectiva dos padrões alimentares" (Processo n0475311/2010-8 - MCT/CNPQ Universal).

A parte da pesquisa abordada neste artigo apresenta a coleta de dados realizados em um assentamento rural amazônico localizado na área do Rio Madeira, amparado em dados coletados em dois trabalhos de campo. O primeiro trabalho de campo ocorreu em julho de 2015 na enchente, quando foram realizados os primeiros contatos com as instituições municipais e com os moradores do assentamento rural. $\mathrm{Na}$ sede do município de Nova Olinda do Norte, realizamos as pesquisas no Instituto Nacional de Colonização e Reforma Agrária (INCRA), no Instituto de Desenvolvimento Agropecuário e Florestal Sustentável do Estado do Amazonas (IDAM) e na Secretaria Municipal de Educação de Nova Olinda do Norte, para conversar com a nutricionista responsável por organizar o cardápio da merenda escolar no município. Este momento foi fundamental para a realização da coleta de informações sobre os assentados e dos dados educacionais encontrados na escola onde os entrevistados se encontravam matriculados permitindo analisar a vivência dos alunos entrevistados, pois somente assim seria possível ter o conhecimento sobre o número de turmas, professores, alunos, sobre o preparo da merenda escolar e sobre a origem da mesma. 
ANÁLISES SOBRE MUDANÇAS NOS HÁBITOS ALIMENTARES DE CRIANÇAS MORADORAS DO ASSENTAMENTO PAQUEQUER, NOVA OLINDA DO NORTE- AM.

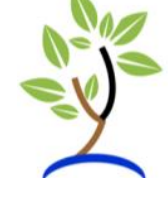

O segundo trabalho de campo ocorreu em janeiro de 2016, na vazante dos rios amazônicos. Em virtude das entrevistas terem sido realizadas no momento das férias escolares, os questionários precisaram ser aplicados aos alunos em sua própria residência. Por serem menores de idade, houve a necessidade de solicitação da autorização de seus responsáveis no ato da realização das entrevistas. Foi utilizado um TCLE (Termo de Compromisso Livre e Esclarecido) para que se minimizassem os riscos da participação dos entrevistados neste trabalho de pesquisa. O questionário foi organizado a partir do modelo utilizado no Trabalho de Conclusão de Curso da nutricionista Suze Maria de Castro Moreira, do curso de Nutrição de Coari- AM, com o título: Abordagens sobre práticas alimentares e educação nutricional com adolescentes de uma escola pública de Coari/ AM. No entanto, todas as perguntas foram adaptadas para que pudessem vir a atender as necessidades propostas no projeto.

A pesquisa apresenta dados qualitativos e quantitativos. Definiu-se que a pesquisa deveria ser realizada com $50 \%$ dos alunos regularmente matriculados no Ensino Fundamental II do 60 ao 9․ Assim, de um total de 60 alunos matriculados, participaram da pesquisa 12 meninos e 18 meninas, totalizando o universo de 30 alunos entrevistados. A realização dessa pesquisa foi importante para nos ajudar a identificar as influências da adoção de novos padrões alimentares no cotidiano dos entrevistados, permitindo perceber se nessas áreas estaria havendo ou não, o comprometimento da segurança alimentar das crianças envolvidas na pesquisa.

Foram utilizados formulários contendo 7 perguntas com a finalidade de verificar que tipo de alimentos estão sendo consumidos no café da manhã, no lanche e no almoço. Ao longo da realização da pesquisa foram registradas conversas informais com a família dos entrevistados para identificar a situação econômica dos participantes. 
ANÁLISES SOBRE MUDANÇAS NOS HÁBITOS ALIMENTARES DE CRIANÇAS MORADORAS DO ASSENTAMENTO PAQUEQUER, NOVA OLINDA DO NORTE- AM.

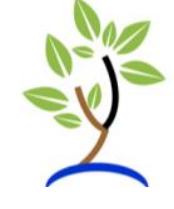

\section{RESULTADOS E DISCUSSÕES}

De acordo com Lencioni (2013), a intensificação da capitalização do campo, a grande diversidade das atividades que são desenvolvidas no campo acrescidas da revolução nos transportes e na comunicação aproximaram o mundo rural do mundo urbano, onde a urbanização do campo é entendida como um conjunto de aspectos de transformação do campo sob a influência da cidade, independente da distância física entre eles. Neste sentido, percebemos que no cotidiano vivenciado pelas crianças do assentamento rural, mais do que assimilarem os valores urbanos, as mesmas se encontram integradas a eles, pois mesmo que de forma simbólica, os valores culturais requalificaram a vida cotidiana dos habitantes do campo, permitindo que eles incorporem novos padrões alimentares que se diferenciam da alimentação tradicional que um dia foi consumida pelos moradores mais idosos.

O processo de globalização faz com que não se tenha fronteiras para com a troca de informação e/ou mercadorias. Popkin (2006) denomina este processo como a mais recente "transição nutricional" vivenciada pelo homem, pois, embora tal fenômeno se apresente com maior evidência nos ambientes urbanos, a influência deste fenômeno de transição alimentar no meio rural ainda exige muitos estudos sobre essa temática.

O acesso à energia elétrica dentro do assentamento, obtida pelo Programa Luz Para Todos, aumentou o consumo de alimentos congelados por parte das famílias assentadas, assim como, o acesso às propagandas de alimentos industrializados visualizadas nos programas de televisão, colaborou para influenciar as escolhas e as novas preferências alimentares apresentadas pelos entrevistados. O processo de globalização colabora para que não se tenha fronteira para com a troca de informação e/ou mercadorias. Kayser (1990) afirma que o fluxo de pessoas, capitais e mercadorias faz com que se tenha um espaço estreitamente e concretamente ligado à grande cidade, denominando-o como espaços metropolizados. Este fato demonstra que o processo de globalização, além de diminuir a distância entre os lugares 
ANÁLISES SOBRE MUDANÇAS NOS HÁBITOS ALIMENTARES DE CRIANÇAS MORADORAS DO ASSENTAMENTO PAQUEQUER, NOVA OLINDA DO NORTE- AM.

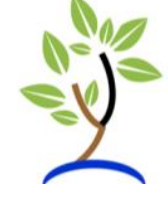

amazônicos, também cria facilidades para a circulação das mercadorias, estabelecendo novos hábitos alimentares para as pessoas que moram em áreas consideradas distantes como as zonas rurais amazônicas.

Com as entrevistas e as conversas realizadas com as crianças, foi possível perceber que as propagandas veiculadas pela televisão contribuem para influenciar no consumo alimentar das mesmas, estimulando para que continuem consumindo alimentos embutidos, instantâneos, bolachas recheadas, salgadinhos e refrigerantes, os quais são comercializados dentro do assentamento. Sobre a ampla comercialização desses produtos, Santos (2006) afirma que a indústria de alimentos e bebidas processadas é uma das maiores do mundo, e movimentam mais de US\$ 1,5 trilhão por ano. Nesse sentido, as multinacionais e os conglomerados gastam milhões de dólares nos sistemas globais de comunicação para estimular novos hábitos alimentares que incorporem os seus produtos.

De acordo com Fonseca et al. (2011) é importante tomarmos consciência de que os alimentos não se deslocam sozinhos pelos canais e que o fluxo dessas mercadorias são controlados por indivíduos e grupos sociais que agem de acordo com suas próprias lógicas, sejam familiares, religiosas, econômicas ou profissionais, pois os alimentos passam por determinados processos que são regidos por fluxos de indivíduos para poder chegar até aos lugares. É assim que, por meio desses fluxos os alimentos chegam a locais distantes das metrópoles, influenciando para que, na zona rural do Amazonas, as pessoas venham a ter acesso, consumindo alimentos que comprometem o seu bem estar, por serem ricos em sal, açúcares e gorduras.

É importante ressaltar que nem sempre o que é mais saboroso é mais saudável. Em virtude disso, ao aprendermos a valorizar o consumo de uma alimentação adequada, capaz de suprir todas as necessidades biológicas, estaremos minimizando os riscos de comprometimento de nossa saúde. Gambardella et al. (1999) citam outro problema sobre a prática de realizar a alimentação diante da televisão ou do computador, como comportamento prejudicial à saúde da sociedade contemporânea, pois este tipo de comportamento auxilia na ingestão de maior 
ANÁLISES SOBRE MUDANÇAS NOS HÁBITOS ALIMENTARES DE CRIANÇAS MORADORAS DO ASSENTAMENTO PAQUEQUER, NOVA OLINDA DO NORTE- AM.

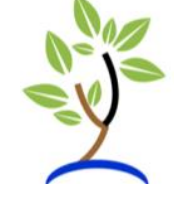

quantidade de alimentos, assim como, a inatividade física gera um desequilíbrio energético, contribuindo para a obesidade.

Segundo Santos (2006), o arroz, o feijão e a farinha de mandioca, que foram, desde o século XVIII, a base do cardápio da maioria da população, estão cada vez mais dando espaço para os produtos industrializados e com maior valor agregado. Ainda sobre isso, Santos (2006) afirma que logo vamos ter os alimentos transgênicos nesta competição. Nos últimos 10 anos o consumo anual de feijão caiu de 12 kg, por brasileiro, para 9,5 kg. A farinha passou a ocupar o $38^{\circ}$ lugar no mercado alimentar e em alguns Estados se planta cada vez menos feijão. De fato, o que está acontecendo é muito ruim, principalmente para a população mais pobre, pois em virtude do baixo poder aquisitivo essa população acaba consumindo os produtos ultraprocessados e os embutidos que são mais baratos que as frutas e verduras.

Sobre o consumo alimentar vivenciado nos últimos anos pela população brasileira, nos estudos realizados por Mainardi, a autora afirma que

\begin{abstract}
Ainda foi declarado que houve, nos últimos anos, aumento de despesas com bebidas e infusões de refrigerantes, cervejas e chopes, em detrimento dos gastos com frutas. Cabe ressaltar que esse é um aspecto que vem comprovar tendências de alterações de hábitos alimentares observadas atualmente no Brasil, que são traduzidas pela frequente troca de alimentos naturais, mais saudáveis, por alimentos industrializados, muitas vezes, mais ricos em açúcares e gorduras (MAINARDI, 2005, p. 13).
\end{abstract}

A mudança nos hábitos alimentares da população rural amazonense é visível uma vez que se prefere a praticidade, a rapidez e às vezes o baixo custo em virtude da pouca renda que essas famílias possuem. O grande problema é que ao consumir produtos industrializados a chance de adquirir problemas com a saúde, por conta de não ter uma alimentação saudável, cresce, fazendo com que diminua a desnutrição, mas aumente os casos de obesidades, hipertensão e diabetes. Coutinho et al. (2008), comentam que ao mesmo tempo em que se assiste à redução contínua dos casos de desnutrição, que é um problema causado pela insuficiência de determinados nutrientes, sendo um problema que se não tratado pode levar a morte e que ocorre principalmente em locais em que se vive em extrema pobreza, são observadas 
ANÁLISES SOBRE MUDANÇAS NOS HÁBITOS ALIMENTARES DE CRIANÇAS MORADORAS DO ASSENTAMENTO PAQUEQUER, NOVA OLINDA DO NORTE- AM.

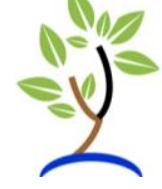

prevalências crescentes de excesso de peso, contribuindo com o aumento das doenças crônicas não transmissíveis.

Michael Moss (2015) aponta informações sobre como a indústria alimentícia moderna ajudou a criar uma epidemia de obesidade planetária, revelando os resultados de uma reportagem explosiva e reveladora ao afirmar que os alimentos que se encontram nas prateleiras dos supermercados são cuidadosamente manipulados por cientistas para potencializarem os seus sabores. O autor demonstra que diferentes corporações da indústria alimentícia "otimiza" esses alimentos para proporcionar ao consumidor algo que pode ser traduzido como o "ponto da felicidade".

\begin{abstract}
Há outro aspecto pouco conhecido no marketing de gêneros alimentícios que reflete sua meticulosidade em estabelecer públicos-alvo. A natureza aparentemente estável e familiar desses supermercados é uma ilusão. O estabelecimento que você frequenta hoje não será o mesmo daqui a um mês [...] os fabricantes costumam alterar seus principais produtos, na maioria das vezes de forma sutil, com mudanças que vão do tamanho das embalagens, passando pela cor e pelo sabor [...]No jargão dos engenheiros dos produtos, Moskowitz aponta na chamada "otimização" e não tem vergonha de relatar as suas façanhas: "Otimizei sopas", contou ele. "Otimizei pizzas. Otimizei molhos para saladas e picles. Nesse campo, eu sou o homem que muda o jogo (MOSS, 2015, p. 59-60).
\end{abstract}

Os meses direcionados para a realização da pesquisa permitiram verificar como o consumo desses alimentos "otimizados" ou industrializados se fazem presentes na mesa dos entrevistados. A pesquisa de campo realizada neste projeto permitiu observar que cerca de $93 \%$ dos entrevistados tomam café da manhã e que esta alimentação é feita com café, leite, pão, manteiga, biscoitos e bolachas. Do total, 19 responderam que incluem o suco natural e 8 responderam que incluem o suco artificial em seu café da manhã. Apenas 1 entrevistado respondeu que no café costuma comer macaxeira, beiju e cará, demonstrando que a maioria dos entrevistados consomem produtos ultraprocessados em seu café da manhã.

Ao responderem sobre o tipo de alimento que consumiam no almoço, foi apresentado aos entrevistados mais de uma opção, logo, do total de alunos, cerca de $50 \%$ consomem no almoço os embutidos e enlatados, $90 \%$ o frango congelado, $66 \%$ 
ANÁLISES SOBRE MUDANÇAS NOS HÁBITOS ALIMENTARES DE CRIANÇAS MORADORAS DO ASSENTAMENTO PAQUEQUER, NOVA OLINDA DO NORTE- AM.

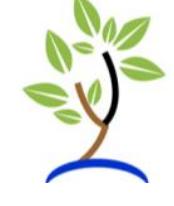

a carne bovina, $76 \%$ comem verduras, $70 \%$ consomem peixe e $60 \%$ tomam sopa no almoço. Apenas $20 \%$ trocam o almoço por lanches.

Questionados sobre o que levavam em consideração na hora de comer e podendo escolher mais de uma opção, cerca de $60 \%$ dos entrevistados responderam que priorizavam a vontade de comer na hora da refeição, cerca de $40 \%$ afirmaram que valorizam o sabor dos alimentos e o hábito de estar com a família no momento da alimentação por considerarem este um momento do encontro, o qual para eles é muito importante. Cerca de $46 \%$ consideraram apenas a fome e cerca de $15 \%$ consumiam o alimento sem ter a preocupação de mastigar, ingerindo com rapidez e sem apresentar nenhuma preocupação com o valor nutricional desses alimentos.

Podendo escolher mais de uma opção e citando 3 alimentos, os entrevistados foram questionados sobre quais alimentos fazem bem à sua saúde, assim, cerca de $53 \%$ consideraram como alimentos nutritivos as frutas e os legumes, cerca de $40 \%$ informaram que o peixe, o feijão e o frango seriam considerados alimentos saudáveis e 30\% consideraram que carboidratos como arroz e macarrão, são saudáveis.

Os alunos foram questionados sobre os alimentos consumidos que não fazem bem à saúde. Assim, citando 3 alimentos, cerca de 53\% dos entrevistados afirmaram que o consumo de refrigerante é prejudicial para a sua saúde, cerca $73 \%$ disseram que o consumo de salgados e frituras é prejudicial. Cerca de $26 \%$ disseram que o consumo de doces é prejudicial e cerca de $36 \%$ afirmaram que os enlatados e embutidos são considerados prejudiciais à saúde. Apenas $10 \%$ dos entrevistados afirmaram considerar o peixe e o macarrão instantâneo como alimentos prejudiciais.

Cerca de $83 \%$ dos entrevistados disseram que aprenderam algo sobre alimentação durante as aulas da escola; cerca de $10 \%$ disse que não lembram e cerca de $7 \%$ disse que não aprenderam nada.

Não foi possível observar entre os moradores dos assentamentos, pais dos entrevistados, uma preocupação com a segurança alimentar, uma vez que eles não demonstraram preocupação em que seus filhos continuem consumindo alimentos industrializados. A única preocupação que eles têm é a de alimentar-se, ou seja, de 
ANÁLISES SOBRE MUDANÇAS NOS HÁBITOS ALIMENTARES DE CRIANÇAS MORADORAS DO ASSENTAMENTO PAQUEQUER, NOVA OLINDA DO NORTE- AM.

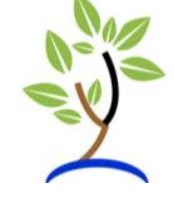

saciar a fome. A possibilidade de se alimentar de forma adequada está mais distante do que antes, pois hoje o acesso e a compra de alimentos industrializados se tornaram mais fáceis dentro do assentamento. O fato de não se preocupar com a segurança alimentar, faz com que as pessoas adquiram mais doenças, pois uma alimentação balanceada é a segurança para a obtenção de uma vida saudável.

Com essa pesquisa foi possível constatar que a maioria dos entrevistados ainda têm o hábito de tomar café da manhã. No entanto, a prática de consumir alimentos como tubérculos cozidos, tapioca e beiju já não está mais presente como antigamente. Ao responderem o questionamento sobre o que consumiam em sua primeira alimentação matinal, respondiam que era café, pão, bolachas e biscoitos, pois esses alimentos podem ser encontrados dentro do assentamento, por isso é mais prático e menos trabalhoso comprá-los.

Ficou nítido que os enlatados, embutidos, refrigerantes, salgados, bolachas recheadas e os pacotes com salgadinhos estão cada vez mais presentes no regime alimentar dos filhos dos assentados. Muitos preferem comer estes alimentos em vez do peixe, da carne, das frutas e dos tubérculos amazônicos. Durante as entrevistas, foi possível constatar o número reduzido de entrevistados consumindo verduras e legumes na hora do almoço, pois esse hábito está sendo abandonado, mesmo sabendo dos benefícios que estes alimentos trazem para a saúde dessas crianças.

Embora $83 \%$ dos entrevistados tenham afirmado que já tinham estudado na Escola sobre a importância de realizar uma alimentação saudável em seu cotidiano, afirmando que sabiam dos riscos que o consumo de determinados alimentos industrializados podem trazer para sua saúde, os mesmos afirmaram que continuariam consumindo os produtos industrializados em suas refeições pela rapidez de seu preparo e pelo fato de que as famílias têm outras despesas e por isso, preferem priorizar o pagamento de suas contas, minimizando assim o direcionamento dos custos na compra de frutas, verduras e de alimentos mais saudáveis. 
ANÁLISES SOBRE MUDANÇAS NOS HÁBITOS ALIMENTARES DE CRIANÇAS MORADORAS DO ASSENTAMENTO PAQUEQUER, NOVA OLINDA DO NORTE- AM.

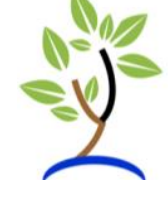

\section{CONCLUSÃO}

É fato que, as políticas públicas que estimularam nos ultimos anos a redução da pobreza e da fome no Brasil também colaboraram para a instalação de uma insegurança alimentar em todo o país. Isso é preocupante, pois não basta apenas acabar com a fome, é necessário que cada ser humano consiga suprir suas necessidades básicas, tendo em sua cesta básica alimentos de qualidade e em quantidade adequadas para seu consumo. No momento que a alimentação de uma pessoa não é balanceada e saudável, sua saúde pode ficar comprometida. Por isso, há uma real necessidade de realizar o consumo de uma alimentação saudável, balanceada e com qualidade e quantidades corretas de calorias.

É importante criar no ambiente das escolas rurais do Amazonas, o estímulo a informações que favoreçam ao desenvolvimento de bons hábitos alimentares, resgatando os hábitos alimentares vivenciados pelos povos tradicionais da Amazônia, com a finalidade de minimizar o avanço das doenças associadas ao tipo de consumo alimentar, as quais nos últimos anos estão sendo diagnosticadas nas zonas rurais do Amazonas.

A população rural amazonense está cada dia consumindo mais produtos industrializados e consumindo menos frutas, verduras, legumes e hortaliças. Essa afirmativata também foi constatada entre os entrevistados moradores do assentamento onde realizamos a pesquisa. Este fato pode estar associado ao novo estilo de vida por eles adotado, pois esses comportamentos aumentam as chances de futuramente essas crianças contraírem doenças crônicas que estão inteiramente associadas ao tipo de alimentação inadequada realizada em seu cotidiano.

Percebemos durante a realização desse trabalho que o consumo de alimentos industrializados tem espaço no cotidiano dos assentados pelo estreito laço que os mesmos estabelecem com a zona urbana do município de Nova Olinda do Norte. No entanto, é importante ressaltar que não cabe a nós estabelecer o julgamento sobre 
ANÁLISES SOBRE MUDANÇAS NOS HÁBITOS ALIMENTARES DE CRIANÇAS MORADORAS DO ASSENTAMENTO PAQUEQUER, NOVA OLINDA DO NORTE- AM.

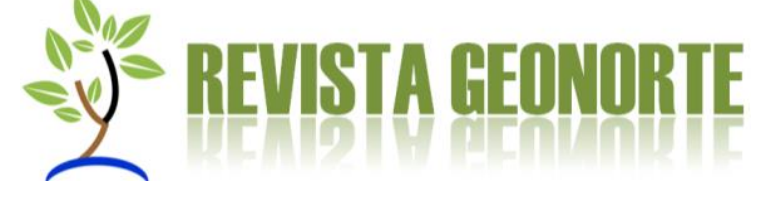

como essas crianças estão se alimentando, pois fazer isso seria privá-los do acesso aos novos hábitos vivenciados nas sociedades contemporâneas.

O grande problema reside no fato dessas crianças estarem deixando de consumir alimentos essenciais para a sua saúde, tendo em vista que antes os hábitos alimentares regionais amazônicos advinham de produtos naturais produzidos principalmente em atividades agrícolas familiares. Por isso, é necessário que a população amazônica tome a consciência da importância de se aprender a ter hábitos alimentares saudáveis para que conquistem qualidade de vida e evitem assim problemas de saúde associadas com o consumo de uma má qualidade alimentar.

\section{REFERÊNCIAS}

COUTINHO, J. G.; GENTIL, P. C.; TORAL, N. A desnutrição e obesidade no Brasil: o enfrentamento com base na agenda única da nutrição. Cad. Saúde Pública, Rio de Janeiro, 24 Sup2:S332-S340, 2008. Disponível em: http://www.scielosp.org/pdf/csp/v24s2/18. Acesso em: 17 de mai. de 2016.

FONSECA, A. B.; SOUZA, T. S. N.; FROZI, D. S., PEREIRA, R. A. Modernidade alimentar e consumo de alimentos: contribuições sócio antropológicas para a pesquisa em nutrição. Disponível em: www.scielosp.org/pdf/csc/v16n9/a21v16n9.pdf. Acesso: 07 de jan. de 2016.

GAMBARDELLA, A. M.D. FRUTUOSO, M. F. P.; FRANCHI, C. Prática Alimentar de Adolescentes. Revista de Nutrição, v.12, n. 1, p 55-63. Jan/abr. 1999.

Institudo Brasileito de Geografia e Estatística - IBGE. Disponível em www.ibge.com.gov.br. Acesso em 27 de out. de 2016.

LENCIONI, S. Metropolização do espaço: processos e dinâmicas. Metropolização do espaço: gestão territorial e relações urbano-rurais. Rio de Janeiro: Consequência, 2013. 17-34.

KAYSER, B. L' espace non-metropolisé du terrioire français. In: KAYSER, B. et alii. Géographe: Entre espace et développement. Toulouse: Presses Universitaires du Mirail, 1990, 284p. 
ANÁLISES SOBRE MUDANÇAS NOS HÁBITOS ALIMENTARES DE CRIANÇAS MORADORAS DO ASSENTAMENTO PAQUEQUER, NOVA OLINDA DO NORTE- AM.

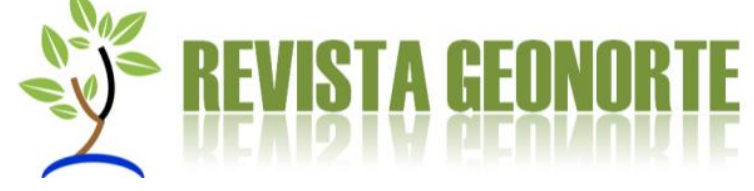

MAINARDI, N. A ingestão de alimentos e as orientações da escola sobre alimentação, sob o ponto de vista do aluno concludente do ensino fundamental. [Mestrado]. Piracicaba: Universidade de São Paulo; 2005.

MONTEIRO, S. M. C. Abordagens sobre práticas alimentares e educação nutricional com adolescentes de uma escola pública de Coari/ AM- 2014: 22 f. Monografia (Bacharelado em Nutrição) - Instituto de Saúde e Biotecnologia Universidade Federal do Amazonas. Coari, 2014.

MOSS, M. Sal, açúcar e gordura: como a indústria alimentícia nos fisgou. Tradução: Andrea Gottlieb de Castro Neves. Rio de Janeiro: Editora Intríseca Ltda, 2015.

POPKIN, B.M. 2006. Global nutrition dynamics: the world is shifting rapidly toward a diet linked with non-communicable diseases. Am J Clin Nutr 84:289-98.

SANTOS, C. R. A. dos. O império Mcdonald e a Mcdonalização da sociedade: alimentação, cultura e poder. 2006. Disponível em http:// people.ufpr.br/ andreadore/Antunes.pdf. Acesso em: 07 de jun. de 2016.

Submetido em: 19/06/2017 Aceito para publicação em: 04/11/2017 